\title{
Sense of Abundance is Associated with Momentary Positive and Negative Affect: An Experience Sampling Study of Trait Gratitude in Daily Life
}

\author{
Marianne Simons $^{1}$ (D) . Johan Lataster ${ }^{1,2} \cdot$ Sanne Peeters $^{1,2} \cdot$ Jennifer Reijnders $^{1}$. \\ Mayke Janssens $^{1,2} \cdot$ Nele Jacobs ${ }^{1,2}$
}

Published online: 18 September 2019

(C) The Author(s) 2019

\begin{abstract}
Results are reported from a study examining the association between subdimensions of trait gratitude (appreciation of others, sense of abundance, and simple appreciation, SGRAT, Thomas and Watkins 2003) and daily life affective processing, in order to respond to the acknowledged need for further research on how trait gratitude may contribute to our wellbeing. Using experience sampling methodology actual momentary experiences of positive and negative affect were measured on 7 consecutive days in a sample of 106 respondents (63 women and 43 men, varying in age from 18 to 65 years). Multilevel regression analyses revealed that only sense of abundance was significantly associated with momentary experiences of positive affect (positive association) and negative affect (negative association) in daily life. Our findings add to the theoretical understanding of the underlying pathway of the association between trait gratitude and well-being and provide a practical starting point for gratitude interventions.
\end{abstract}

Keywords Trait gratitude $\cdot$ Sense of abundance $\cdot$ Positive affect $\cdot$ Negative affect $\cdot$ Wellbeing $\cdot$ Experience sampling method

\section{Introduction}

Trait gratitude has been found to be positively associated with subjective well-being (Alkozei et al. 2018; Watkins et al. 2015), as well as negatively associated with depression (Cheng et al. 2015) and anxiety (Millstein et al. 2016; Ruini and Vescovelli 2013). Although trait gratitude is finding its way to clinical practice and positive psychological interventions (Seligman et al. 2006), a recent meta-analysis of gratitude interventions (Davis et al. 2016) showed positive, but still limited and somewhat inconsistent effects.

Marianne Simons

mariannesimons73@gmail.com

1 Faculty of Psychology and Educational Sciences, Open University, Heerlen, The Netherlands

2 Department of Psychiatry and Psychology, School for Mental Health and Neuroscience, Maastricht University Medical Centre, Maastricht, The Netherlands 
This indicates that even though empirical evidence shows well-being and trait gratitude are positively associated, our understanding of how is not yet sufficient to develop truly effective interventions. In this brief report we present research results of an experience sampling study (ESM, Hektner et al. 2007; Stone et al. 1999), exploring how trait gratitude manifests itself in the experience of affect in daily life, to help us better understand the pathway between trait gratitude and well-being.

Considering paths of affective processing (Fredrickson and Branigan 2005; Rowe et al. 2007), assumptions of positive emotions enhancing resilience (Frederickson 2013; Frederickson and Losada 2005) and the possibility of positive affect initiating an upwards spiral of positive emotions (Frederickson and Joiner 2002; Kok et al. 2013), the roots of the benefits of trait gratitude may well be found in the experience of more positive affect and less negative affect throughout the day. Previous research has indeed shown positive associations between gratitude and a general tendency to experience positive affect (Froh et al. 2009; Jans-Beken et al. 2015; McCullough et al. 2004). In the current study however, the actual momentary experiences of positive affect (PA) and negative affect (NA) were measured.

Previous research indicates that different subdimensions of trait gratitude may vary in their individual contribution to aspects of well-being (Deichert et al. 2018; Fagley 2012; Lin 2014). Lin (2014) showed that different components of gratitude vary in their prediction of mental health, finding only significant associations for two components of gratitude (cherish blessings and appreciation of hardship) and not for three others (thanking god, thanking others and cherishing the moment). Fagley (2012) examined the eight components of the Appreciation Scale (Adler and Fagley 2005) and found that a 'have' focus (focus on and valuing what someone has) and ritual (to foster appreciation) were associated with life satisfaction while the other components were not. The multidimensional Short Gratitude and Resentment Questionnaire (SGRAT, Thomas and Watkins 2003) distinguishes three subdimensions. A sense of abundance (SOA), also referred to as a lack of a sense of deprivation (Thomas and Watkins 2003) can be understood as an overall appreciation of life in general; Appreciation of others (AO) as a feeling of acknowledgement and appreciation of the contribution of others to one's achievements (Thomas and Watkins 2003) or well-being (Fagley 2012); and Simple appreciation (SA) or the ability to appreciate or dwell upon little things (Thomas and Watkins 2003) and a mindful awareness of the present moments and a feeling of wonder to nature, beauty or life (Fagley 2012). We examined the associations between actual momentary experiences of affect and these subdimensions.

\section{Methods}

\subsection{Procedure and Sample}

The study was approved by the Research Ethics Committee of the Open University of the Netherlands and followed the American Psychological Association Ethical principles of psychologists and code of conduct. The sample consisted of Dutch speaking adults, approached by graduate students of the Open University Netherlands via either personal contact or social media. As inclusion criteria age (18 and above) and sufficient command of the Dutch language to understand instructions were applied. Also, a written informed consent had to be provided by the participant to be included in the study. Participants were given access to the baseline questionnaire measuring trait gratitude and demographic 
variables after they gave their consent to the careful and secure use of the data for this study, in compliance with their privacy rights. Subsequently they were given access to the ESM based smartphone app (RealLife ${ }^{\mathrm{TM}}$ Exp, vers. 2.4.8; Lifedata LLC 2015), programmed to signal at unpredictable moments in ten 90-min time blocks between 7.30 a.m. and 22.30 p.m. on seven consecutive days. At each signal, respondents were asked to fill out the same short questionnaire, containing PA and NA items, presented in a random order at every run. After $15 \mathrm{~min}$ the signal expired and the questionnaire was no longer accessible. 106 respondents -43 men and 63 women, age 18-65 (Mean=38.7; SD=14.5), $51 \%$ higher education, $72 \%$ in a relationship - responded to at least $33 \%$ of all signals (Mean $=45, S D=12.10$, range 23-68) and could be included in the analysis (Delespaul 1995). A total of 4785 observations was recorded.

\subsection{Measurement}

\subsubsection{Baseline Questionnaire}

Gender, age, education level and having a life partner were measured as they have been found to be associated with positive and negative affect (Brans et al. 2013; Lambert et al. 2012b), and trait gratitude (Jans-Beken et al. 2017). Subdimensions of trait gratitude were measured by the Short Gratitude and Resentment Questionnaire (SGRAT-NL; Thomas and Watkins 2003; Jans-Beken et al. 2015). Mean scores were calculated for SGRAT_SOA, SGRAT_SA and SGRAT_AO, with reliability scores of respectively (Crohnbach's) $\alpha=.85$, $\alpha=.81$ and $\alpha=.75$.

\subsubsection{Experience Sampling Method}

Consistent with previous studies (Jacobs et al. 2013; Wouters et al. 2018) PA was measured by three items (PA-scale: I feel 'cheerful', 'satisfied', 'happy'), and NA by four items (NA-scale: I feel 'insecure', 'anxious', 'down', 'guilty'), scored on a 7-point Likert scale $(1=$ not at all to $7=$ very $)$. Mean scores were calculated. Reliability was sufficient for both PA (Crohnbach's $\alpha_{(\text {within })}=.77$; Crohnbach's $\left.\alpha_{\text {(aggregated) }}=.94\right)$ and NA (Crohnbach's $\alpha_{(\text {within })}=.65$; Crohnbach's $\alpha_{\text {(aggregated) }}=.95$ (Huang and Weng 2012).

\subsection{Analysis}

For statistical analyses, SPSS (version 24) was used. With multilevel regression analyses the associations between (the subscales of) trait gratitude (level 2, predictor variable) and the experience of respectively momentary PA and NA in daily life (level 1, outcome variable) were examined. Since the experiences of PA and NA are expected to be related (Frederickson 2013; Keyes 2005), they were included as a control predictor variable. A random intercept and slope for the association between PA and NA were included. For the predictor variables (measured with ESM) person-mean-centered scores were used (Curran and Bauer 2011; Snippe et al. 2017). Trait gratitude and age were group-centered (Enders and Tofighi 2007). 


\section{Results}

Results of both multilevel regression analyses are presented in Table 1, showing a positive significant association between the experience of momentary PA (Mean $=4.96$; $S D=1.202)$ and the subscale SOA $(M e a n=7.12 ; S D=1.44)$. The experience of momentary NA $($ Mean $=1.79 ; S D=.965)$ is negatively associated with SOA. The subscales SA $($ Mean $=7.55 ; S D=1.06)$ and AO $($ Mean $=7.00 ; S D=1.22)$ are neither significantly associated with momentary PA nor with NA. Furthermore, analyses show negative associations between momentary PA and NA, which also varies among individuals (see random effects).

\section{Discussion}

Our results show a positive association between a sense of abundance and momentary positive affect and a negative association with momentary negative affect. Appreciation of others was not associated with either positive or negative affect, nor was simple appreciation. These results do not only add to earlier research findings concerning the association between well-being and trait gratitude (i.e. Alkozei et al. 2018; Watkins et al. 2015), but may shed light on the affective pathway between trait gratitude and well-being. Interpreting Lin's (2014) cherish blessings and Fagley's (2012) 'have' focus' as an overall appreciation

Table 1 Associations between subscales of trait gratitude (SGRAT) and momentary PA and NA

\begin{tabular}{|c|c|c|c|c|}
\hline & \multicolumn{2}{|l|}{ PA } & \multicolumn{2}{|l|}{ NA } \\
\hline & $\mathrm{B}(\mathrm{SE})$ & $95 \% \mathrm{CI}$ & $\mathrm{B}(\mathrm{SE})$ & $95 \% \mathrm{CI}$ \\
\hline \multicolumn{5}{|l|}{ Fixed effects } \\
\hline $\mathrm{cSOA}$ & $.23 *(.06)$ & .11 to .34 & $-.23 *(.05)$ & -.33 to -.12 \\
\hline $\mathrm{cSA}$ & $.16(.10)$ & -.03 to .36 & $-.05(.09)$ & -.22 to .12 \\
\hline $\mathrm{cAO}$ & $.03(.08)$ & -.13 to .18 & $-.00(07)$ & -14 to .13 \\
\hline $\mathrm{cNA}$ & $-.75^{*}(.05)$ & -.84 to -.66 & $N A$ & $N A$ \\
\hline cPA & $N A$ & $N A$ &.$- \mathbf{3 0} *(.02)$ & -.35 to -.25 \\
\hline cAge & $.01(.01)$ & -.01 to .02 & $-.00(.01)$ & -.01 to .01 \\
\hline Gender & $.21(.17)$ & -.12 to .55 & $.19(.15)$ & -.10 to .48 \\
\hline Education & $-.31(.17)$ & -.66 to .03 & $.24(.16)$ & -.06 to .55 \\
\hline Relationship & $.30(.19)$ & -.07 to .67 & $-.16(.16)$ & -.49 to .16 \\
\hline \multicolumn{5}{|l|}{ Random effects } \\
\hline Intercept & $.68 *(.10)$ & .51 to .90 & $.52 *(.08)$ & .40 to .70 \\
\hline cNA &. $\mathbf{1 4} *(.03)$ & .09 to .22 & $N A$ & $N A$ \\
\hline cPA & $N A$ & $N A$ & $.05 *(.01)$ & .04 to .08 \\
\hline N/observations & $106 / 4785$ & & $106 / 4785$ & \\
\hline
\end{tabular}

$\mathrm{cSOA}=$ deviation from the group mean of Sense of Abundance; $\mathrm{cSA}=$ deviation from the group mean of Simple Appreciation; $\mathrm{cAO}=$ deviation from the group mean of Appreciation of Others; cNA=deviation from the person mean of Momentary Negative Affect; cPA=deviation from the person mean of Momentary Positive Affect; cAge =deviation from the group mean of Age; Gender $0=$ female and $1=$ male; Education $0=$ low and $1=$ high; Relationship $0=$ not in relationship and $1=$ in relationship

$* p<.001$ 
of life in general (Watkins et al. 2003), our results are in line with their findings as discussed in the Introduction and support the assumption that a sense of abundance in particular is associated with momentary positive and negative affect.

Considering the adaptive value of positive affect (i.e. Frederickson and Losada 2005; Rowe et al. 2007), this underlying mechanism may also involve an interplay between experiences of positive and negative affect throughout the day. The assumed negative association between positive and negative affect (i.e. Keyes 2005; Watson and Naragon-Gainey 2010), which was revealed in our analysis, fits Frederickson's (2013) argument that positive affect (emotions) can enhance resilience and protect against (the effects of) negative affect and result in more positive affect.

\subsection{Critical Notes and Further Research}

In ESM research a sample of 106 respondents can be considered sufficiently large (Ohly et al. 2010) to provide a reliable presentation of the daily experiences of momentary positive and negative affect. Including a larger sample in future research, would allow for analysis on aggregated level, enabling the inclusion of a greater variety of response patterns of affect, such as the variability of positive and negative affect (Jacobs et al. 2013) or the individual change in respectively positive and negative affect, representing response patterns to pleasant and unpleasant experiences (Jacobs et al. 2013). Our results encourage us to include these variables on aggregated level in future research in a larger sample to refine the interpretation of the results of the current study and further enhance our understanding of the affective processes underlying the benefits of trait gratitude.

Mean scores of our core variables were comparable with mean scores of similar samples in previous studies (Jans-Beken et al. 2015; Wouters et al. 2018). However, the composition of the sample was affected by our choice of method, as participation required using a smartphone and was time consuming. In comparison with the general Dutch population, our sample was higher educated (51\% vs. 28.5\%) and slightly younger (38.7 vs. 41.8 years). Also, female respondents were somewhat overrepresented (59\% vs. 50\%) (opendata.cbs. $\mathrm{nl}$ ). Future research of associations between momentary affect and trait gratitude would benefit from a more representative sample, which also allows for more accurate analysis of the role of the included confounders. Also, other demographic variables than those included (i.e. employment, income, health) may have affected our outcomes and should be accounted for in further research. Not finding any significance of our included confounders should not only make us hesitant in drawing conclusions regarding these demographic variables, but also challenge us to reconsider what confounders are most relevant to include in future research.

Finally, issues such as repetition of questions, participation fatigue, timing of a signal etc. may have affected responses (Bolger et al. 2003). However, we are confident that the benefits of ESM added to the reliability and ecological validity of our data as was done in previous ESM research (i.e. Brans et al. 2013; Myin-Germeys et al. 2009).

\subsection{Practical Implications}

Interventions that aim to trigger a sense of abundance or enhance the overall appreciation of life in general are worthwhile further looking into and may serve as a practical starting point for the further development of effective gratitude interventions. Examples are respectively narrative methods such as a gratitude journal (Lambert et al. 2012a) or life review 
interventions (Korte et al. 2012) with a focus on gratitude and appreciation. The possibility of trait gratitude facilitating an upwards spiral of positive affect can be recognised in the assumption that gratitude interventions might help to defy the hedonic treadmill (Davis et al. 2016), resulting in long-term shifts in satisfaction (Seligman et al. 2005).

\subsection{Conclusion}

Although our research design does not allow for conclusions regarding the direction of the found associations, we may have revealed part of the affective pathway between trait gratitude and positive outcomes related to mental health and well-being. Shedding light on the positive association between the subdimension sense of abundance and momentary positive affect and its negative association with momentary negative affect has elaborated our theoretical understanding of the psychological value of trait gratitude and provided us with a practical starting point for further development of effective gratitude interventions.

Acknowledgements We are grateful to Alie de Boer, Yvette Hooijman, Marleen Donk, Margo Varwijk, and Gerdien Noltes for their assistance in the ESM data collection.

\section{Compliance with Ethical Standards}

Conflict of interest The authors declare that there is no conflict of interest regarding this study.

Open Access This article is distributed under the terms of the Creative Commons Attribution 4.0 International License (http://creativecommons.org/licenses/by/4.0/), which permits unrestricted use, distribution, and reproduction in any medium, provided you give appropriate credit to the original author(s) and the source, provide a link to the Creative Commons license, and indicate if changes were made.

\section{References}

Adler, M. G., \& Fagley, N. S. (2005). Appreciation: Individual differences in finding value and meaning as a unique predictor of subjective well-being. Journal of Personality, 73, 79-114.

Alkozei, A., Smith, R., \& Killgore, W. D. (2018). Gratitude and subjective wellbeing: A proposal of two causal frameworks. Journal of Happiness Studies, 19(5), 1519-1542.

Bolger, N., Davis, A., \& Rafaeli, E. (2003). Diary methods: Capturing life as it is lived. Annual Review of Psychology, 54(1), 579-616.

Brans, K., Koval, P., Verduyn, P., Lim, Y. L., \& Kuppens, P. (2013). The regulation of negative and positive affect in daily life. Emotion, 13(5), 926-939.

Cheng, S. T., Tsui, P. K., \& Lam, J. H. M. (2015). Improving mental health in health care practitioners: Randomized controlled trial of a gratitude intervention. Journal of Consulting and Clinical Psychology, 83(1), 177-186.

Curran, P. J., \& Bauer, D. J. (2011). The disaggregation of within-person and between-person effects in longitudinal models of change. Annual Review of Psychology, 62, 583-619.

Davis, D. E., Choe, E., Meyers, J., Wade, N., Varjas, K., Gifford, A., et al. (2016). Thankful for the little things: A meta-analysis of gratitude interventions. Journal of Counseling Psychology, 63(1), 20-31.

Deichert, N. T., Chicken, M. P., \& Hodgman, L. (2018). Appreciation of others buffers the association of stressful life events with depressive and physical symptoms. Journal of Happiness Studies, 20, 1071-1088.

Delespaul, P. A. E. G. (1995). Assessing schizophrenia in daily life, the experience sampling method. Maastricht: Maastricht University.

Enders, C. K., \& Tofighi, D. (2007). Centering predictor variables in cross-sectional multilevel models: A new look at an old issue. Psychological Methods, 12(2), 121-138. 
Fagley, N. S. (2012). Appreciation uniquely predicts life satisfaction above demographics, the Big 5 personality factors, and gratitude. Personality and Individual Differences, 53, 59-63.

Frederickson, B. L. (2013). Updated thinking on positivity ratios. The American Psychologist, 68(9), 814-822.

Fredrickson, B. L., \& Branigan, C. A. (2005). Positive emotions broaden the scope of attention and thoughtaction repertoires. Cognition and Emotion, 19, 313-332.

Frederickson, B. L., \& Joiner, T. (2002). Positive emotions trigger upward spirals toward emotional wellbeing. Psychological Science, 13(2), 172-175.

Frederickson, B. L., \& Losada, M. F. (2005). Positive affect and the complex dynamics of human flourishing. The American Psychologist, 60(7), 678-686.

Froh, J. J., Kashdan, T. B., Ozimkowski, K. M., \& Miller, N. (2009). Who benefits the most from a gratitude intervention in children and adolescents? Examining positive affect as a moderator. Journal of Positive Psychology, 4, 408-422.

Hektner, J. M., Schmidt, J. A., \& Csikszentmihalyi, M. (2007). Experience sampling method. Measuring the quality of everyday life. London: Sage Publications.

Huang, P. H., \& Weng, L. J. (2012). Estimating the reliability of aggregated and within-person centered scores in ecological momentary assessment. Multivariate behavioural research, 47(3), 421-441.

Jacobs, N., Menne-Lothmann, C., Derom, C., Thiery, E., Van Os, J., \& Wichers, M. (2013). Deconstructing the familiality of variability in momentary negative and positive affect. Acta Psychiatrica Scandinavica, 127(4), 318-327.

Jans-Beken, L., Lataster, J., Leontjevas, R., \& Jacobs, N. (2015). Measuring gratitude: A comparative validation of the Dutch Gratitude Questionnaire (GQ6) and Short Gratitude, Resentment, and Appreciation Test (SGRAT). Psychologica Belgica, 55(1), 19-31.

Jans-Beken, L., Lataster, J., Peels, D., Lechner, L., \& Jacobs, N. (2017). Gratitude, psychopathology and subjective well-being: Results from a 7.5-month prospective general population study. Journal of Happiness Studies. https://doi.org/10.1007/s10902-017-9893-7.

Keyes, C. L. M. (2005). Mental illness and/or mental health? Investigating axioms of the complete state model of health. Journal of Consulting and Clinical Psychology, 73, 539-548.

Kok, B. E., Coffey, K. A., Cohn, M. A., Catalino, L. I., Vacharkulksemsuk, T., Algoe, S. B., et al. (2013). How positive emotions build physical health: Perceived positive social connections account for the upward spiral between positive emotions and vagal tone. Psychological Science, 24(7), 1123-1132.

Korte, J., Bohlmeijer, E., Cappeliez, P., Smit, F., \& Westerhof, G. (2012). Life review therapy for older adults with moderate depressive symptomatology: A pragmatic randomized controlled trial. Psychological Medicine, 42, 1163-1173.

Lambert, N. M., Fincham, F. D., \& Stillman, T. F. (2012a). Gratitude and depressive symptoms: The role of positive reframing and positive emotion. Cognition and Emotion, 26, 615-633.

Lambert, N. M., Gwinn, A. M., Baumeister, R. F., Strachman, A., Washburn, I. J., Gable, S. L., et al. (2012b). A boost of positive affect: The perks of sharing positive experiences. Journal of Social and Personal Relationships, 30(1), 24-43.

Lifedata, LLC. (2015). RealLife Exp (Version 2.4.8) [Mobile application software]. www.lifedataco rp.com.

Lin, C. C. (2014). A higher-order gratitude uniquely predicts subjective well-being: Incremental validity above the personality and a single gratitude. Social Indicators Research, 119(2), 909-924.

McCullough, M. E., Tsang, J. A., \& Emmons, R. A. (2004). Gratitude in intermediate affective terrain: Links of grateful moods to individual differences and daily emotional experience. Journal of Personality and Social Psychology, 86(2), 295-309.

Millstein, R. A., Celano, C. M., Beale, E. E., Beach, S. R., Suarez, L., Belcher, A. M., et al. (2016). The effects of optimism and gratitude on adherence, functioning and mental health following an acute coronary syndrome. General Hospital Psychiatry, 43, 17-22.

Myin-Germeys, I., Oorschot, M., Collip, D., Lataster, J., Delespaul, P., \& van Os, J. (2009). Experience sampling research in psychopathology: Opening the black box of daily life. Psychological Medicine, 39, 1-15.

Ohly, S., Sonnentag, S., Niessen, C., \& Zapf, D. (2010). Diary studies in organizational research: An introduction and some practical recommendations. Journal of Personnel Psychology, 9, 79-93.

Rowe, G., Hirsch, J., \& Anderson, A. K. (2007). Positive affect increases the breadth of attentional selection. Proceedings of the National Academy of Sciences of the United States of America, 104(1), 383-388.

Ruini, C., \& Vescovelli, F. (2013). The role of gratitude in breast cancer: Its relationships with posttraumatic growth, psychological well-being and distress. Journal of Happiness Studies, 14(1), 263-274. 
Seligman, M. E. P., Rashid, T., \& Parks, A. C. (2006). Positive psychotherapy. American Psychologist, $61,774-788$.

Seligman, M. E. P., Steen, T. A., Park, N., \& Peterson, C. (2005). Positive psychology progress: Empirical validation of interventions. American Psychologist, 60, 410-421.

Snippe, E., Jeronimus, B. F., Aan Het Rot, M., Bos, E. H., de Jonge, P., \& Wichers, M. (2017). The reciprocity of prosocial behavior and positive affect in daily life. Journal of Personality, 86, 139-146.

Stone, A. A., Shiffman, S., \& De Vries, M. (1999). Rethinking our self-report assessment methodologies: An argument for collecting ecologically valid, momentary measurements. In D. Kahneman, E. Diener, \& N. Schwarz (Eds.), Well-being: The foundations of hedonic psychology (pp. 26-39). New York: Sage.

Thomas, M., \& Watkins, P. (2003). Measuring the grateful trait: Development of revised GRAT. Poster session presented at the annual convention of the Western Psychological Association, Vancouver, BC, Canada.

Watkins, P. C., Uhder, J., \& Pichinevskiy, S. (2015). Grateful recounting enhances subjective well-being: The importance of grateful processing. The Journal of Positive Psychology, 10(2), 91-98.

Watkins, P. C., Woodward, K., Stone, T., \& Kolts, R. (2003). Gratitude and happiness: Development of a measure of gratitude and relationships with subjective well-being. Social Behavior and Personality, $31(5), 431-451$.

Watson, D., \& Naragon-Gainey, K. (2010). On the specificity of positive emotional dysfunction in psychopathology: Evidence from the mood and anxiety disorders and schizophrenia/schizotypy. Clinical Psychological Review, 30(7), 839-848.

Wouters, S., Jacobs, N., Duif, M., Lechner, L., \& Thewissen, V. (2018). Negative affective stress reactivity: The dampening effect of snacking. Stress and Health, 34(2), 286-295. https://doi.org/10.1002/ smi.2788.

Publisher's Note Springer Nature remains neutral with regard to jurisdictional claims in published maps and institutional affiliations. 